\title{
CORRECTION
}

\section{Correction to: Aducanumab: First Approval}

\section{Sohita Dhillon ${ }^{1}$}

Published online: 15 September 2021

(c) Springer Nature Switzerland AG 2021

\section{Correction to: Drugs (2021) 81:1437-1443}

https://doi.org/10.1007/s40265-021-01569-z

The Supplementary file1 (PPTX $493 \mathrm{~kb}$ ) has been updated and replaced.

The original article has been corrected.

Supplementary Information The online version contains supplementary material available at https://doi.org/10.1007/s40265-021-01590-2.

The original article can be found online at https://doi.org/10.1007/ s40265-021-01590-2.

Sohita Dhillon dru@adis.com

1 Springer Nature, Private Bag 65901, Mairangi Bay, Auckland 0754, New Zealand 